\title{
A Research on Customers' Attitudes and Their Preferences Toward Online Shopping Vis-à-vis Offline Shopping with Special Reference to Electric and Electronic Products in India
}

\author{
Anil K.S.Chauhan, Pradeep Suri
}

\begin{abstract}
The increasing no. of netizens in India is likely to increase the chances of online shopping being successful in India. In the present era, it is believed that online shopping has become a popular mode of shopping for the customers because of their changing attitudes and adoption of technological change. With this belief marketers in India are busy in studying customers' attitudes toward online shopping vis-à-vis offline shopping so that they can devise their strategies to satisfy their target customers. The present research study is undertaken to measure and compare customers' attitudes toward online shopping and offline shopping and study their preferred shopping mode for electric and electronic products. This study includes the use of Fishbein's Multi-attributes Attitude Model to measure the attitude of individual customers through the semantic differential rating scale. After calculating the attitude scores, z-Test for sample means is applied for the meaningful comparison of average attitude scores obtained for two samples of online shopping scores and offline shopping scores. Proportions of customers preferring online and offline shopping modes are compared by using $z$ - test. The extent of the population selected for the investigation is geographical boundaries of Dehradun city of Uttarakhand state in India. Statistical analysis of collected data infers that there is evidence of customers' more favorable attitudes toward online shopping vis-a-vis offline shopping for electric and electronic products and that almost half of the population of customers prefers to shop electric and electronic products online.
\end{abstract}

Index Terms: Attitude, Preference, Online Shopping, Offline Shopping, Belief, Intensity of Feelings.

\section{INTRODUCTION}

Online shopping refers to the purchasing of goods or services from a selected store by making the use of the internet. Easy and economic accessibility of internet usage has been boosting the use of online shopping in India. The facility of comparing a product/brand with other alternative products/brands in various product categories based on different attributes such as size, shape, color, price and quality are the reasons behind the transformation of customers' purchase intention into online purchase behavior. A large number of monetary inducements are also making the customers crazy about online shopping. On the contrary, some drawbacks of online shopping such as deception and fraud in delivering the same product as selected by the customer, poor after- sales services, delayed delivery of the product, refund and return dispute, intangible evaluation and comparison of alternatives, lack of quality guarantee etc. persuade the customers to remain with traditional offline shopping. Nowadays, marketers are in quandary. They are apprehensive of losing their customers if they do not devise their strategy and at the same time, they think of retaining those customers who do not prefer online shopping. Thus, it becomes vital for marketers to carefully study the attitudes and preferences of the customers toward online shopping and offline shopping before reaching any conclusion. An attitude is a predisposition that makes an individual behaves favorably or unfavorably for an object. In this study, Fishbein's Multi-attributes Attitude Model is applied to measure the customers' attitudes in quantitative terms and subsequently a meaningful comparison is made between the attitude scores secured for the online shopping and offline shopping.

Fishbein's Multi-attributes Attitude Model suggests that customers form their attitudes toward an object based on their feelings toward each attribute of the object and their beliefs about the object and attribute linkage. Beliefs are acquired by processing the information about various attributes of the object obtained from direct experiences with them and from communication about them received from other sources. Feelings (Liking or Disliking) for each attribute are also formed based on the information and beliefs held about these attributes. Thus, a customer's attitude towards some object is determine by his beliefs and feelings about various attributes of the object as shown in Figure-1. This model helps us determining a numeric value for the overall attitude of a person.

Mathematically, Fishbein's multi-attribute attitude model is represented as follows.

$\mathrm{A}_{0}=\sum \mathrm{B}_{\mathrm{i}} \cdot \mathrm{E}_{\mathrm{i}}$ 


\section{A Research on Customers' Attitudes and Their Preferences Toward Online Shopping Vis-à-vis Offline Shopping with Special Reference to Electric and Electronic Products in India}

Where

Ao is the customer's overall attitude score towards the object (e.g., a good or a service or a cause or an issue or a function) $\mathrm{B}_{\mathrm{i}}=$ The score of the strength of his belief that the object is related to attribute $\mathrm{i}$.

$\mathrm{E}_{\mathrm{i}}=$ The score of his evaluation for attribute $i$ as being important or unimportant.

$i$ varies from 1 to $n$

$n$ stands for the total number of attributes/characteristics.

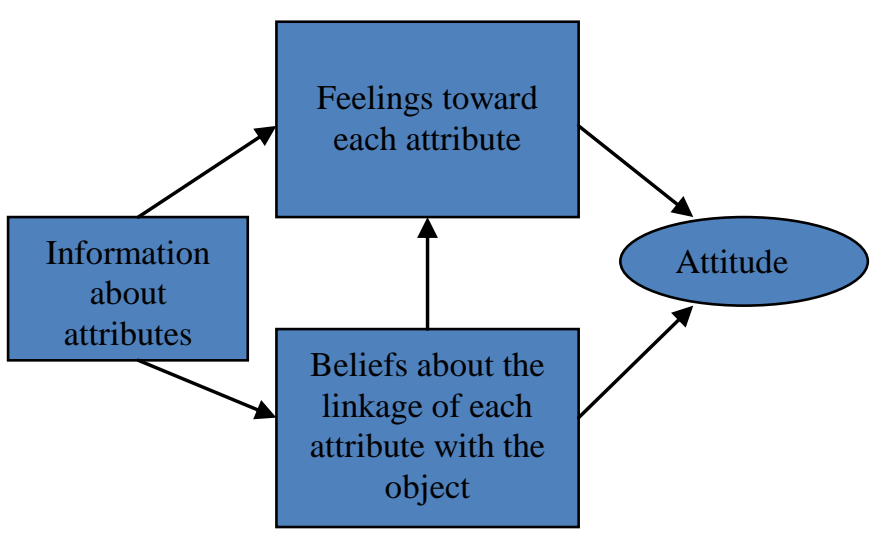

Figure-1: Fishbein's multi-attribute attitude model

\section{LITERATURE REVIEW- A SYNTHESIS}

India is tending towards the largest e-commerce market as unprecedented growth was triggered by a crash in data tariffs. Millions of new users in remote areas are now the elements of netizens' population who are taking advantage of economic data tariffs to use Apps like the Chinese TikTok and local ShareChat. People in urban areas use mobile phones to chat, watch the live telecast of sports, use social media platforms, and of course, to shop. People of rural areas are also shifting their behavioral pattern to multiple usages of mobile phone and online shopping is one of them. The major proportion of internet users in India is of males and the same is concluded for online customers by some research studies. In India, men constituted a two third proportion of online shoppers. Despite this, women do not fall behind in online shopping and digital spending. Studies suggest that online shopping is gaining recognition in the eyes of customers in India at a quick pace. The attitudes of the customers toward online shopping are changing with the time and the change in attitude depends on the attributes of digital shopping mode while it is independent of customers' age groups, occupation, education etc. In India, customers are finding online shopping very useful because of many attributes like filter search, comparative evaluation of alternatives, home delivery etc. At the same time, another proportion of customers feel slightly uneasy about online shopping due to security concerns. Some customers are hostile to online shopping because of the technological complexity involved. Research studies also found that a lot of customers do not prefer online shopping for the products of high unit values despite they possess a favorable attitude towards online shopping i.e. their preference for shopping varies with the category and price of the products. Studies also found that the people who are wired and those who are more time-saving tend to shop online more as compared to those who are not wired and those who have enough time to spend for shopping.

\section{RESEARCH QUESTIONS AND OBJECTIVES}

During the literature review, a lot of research questions came to the mind of the investigators. After the process of elimination, the following research questions were selected for investigation.

$>$ Are customers' attitudes toward online shopping more favorable than those toward offline shopping?

$>$ Does the proportion of customers who prefer to shop online is more than the proportion of those customers who prefer to shop offline.

Selected research questions were transformed into research objectives by using action-oriented terms as written below.

$>$ To measure and compare customers' attitudes toward online shopping and offline shopping.

$>$ To study the preference of customers for online and offline modes of shopping.

$>$ To measure the proportion of customers who prefer to shop online and to compare it with the proportion of those customers who prefer to shop offline.

\section{RESEARCH HYPOTHESES}

Based on the extensive literature review and personal observations of the investigators, anticipated answers to selected research questions were found and transformed into testable hypotheses.

Hypothesis-1: Customers' mean attitude score for online shopping is equal to their mean attitude score for offline shopping.

Hypothesis-2: Proportion of customers who prefer to shop online is almost equal to $50 \%$.

\section{RESEARCH METHODOLOGY}

A. Target Population of the Study: Elements of the population selected for the study were customers of electric and electronic products who shopped online as well as offline. Units available for the selection in the sample were elements of the population. The extent of the population selected for the investigation was geographical boundaries of Dehradun city of Uttarakhand state in India and the time frame of the study was January 2019 to May 2019.

B. Research Design and Elicitation of Required Data: Focusing on the research objectives the study was aimed at describing the characteristics and functions of the customers; therefore a highly structured descriptive research design was used. Since researchers were intended to measure the attitudes and preferences of customers, therefore, primary data were collected through a well-structured questionnaire containing multiple- choice questions to elicit the information of their demographics, dichotomous questions to study their preference for shopping mode and semantic differential rating scales to measure their attitudes. 
In the questionnaire, selected respondents were asked to rate the attributes of shopping namely Availability of variety of products $\left(\mathrm{A}_{1}\right)$, Facility to evaluate and compare the available variants $\left(\mathrm{A}_{2}\right)$, Mode of payment $\left(\mathrm{A}_{3}\right)$, Return and exchange policy $\left(\mathrm{A}_{4}\right)$, Discount and Promotion offers $\left(\mathrm{A}_{5}\right)$, Guarantee of quality of products $\left(\mathrm{A}_{6}\right)$, and Home delivery $\left(\mathrm{A}_{7}\right)$ on a 7 point semantic differential scale ( $1=$ Extremely Unimportant, 2= Moderately Unimportant, 3= Slightly Unimportant, 4= Neither Unimportant nor Important, 5= Slightly Important, 6= Moderately Important and $7=$ Extremely Important) to evaluate the intensity of their feelings toward each attribute as important or unimportant. Respondents were also asked to rate the association between mode of shopping (online shopping and offline shopping) and each attribute on a similar 7 point semantic differential scale ( $1=$ Extremely Unlikely, $2=$ Moderately Unlikely, 3= Slightly Unlikely, 4= Neither Unlikely nor Likely, 5= Slightly Likely, 6= Moderately Likely and 7= Extremely Likely) to ascertain their beliefs about the attributes and shopping mode linkage. Selected respondents were personally approached and handed over the questionnaires to fill in. All the respondents were properly instructed to use the scales to elicit the information sought.

C. Determination of Sample Size and Selection of Sampling Design: Since the investigators couldn't specify a plan to identify the population elements or the sampling units (i.e. determination of sampling frame was not possible for the investigators), therefore probability sampling method could not be used and hence convenience sampling method was used to select the sample for the study. Only those customers who were easily approachable were questioned to ascertain the required information.

As population size was infinite (not known), researchers have used Krejcie and Morgan method to determine sample size. Investigators have assumed that half of the population prefers online shopping. So, $\mathrm{p}=0.5$. With desired confidence level of $95 \%$ and at least $8 \%$ precision, $\mathrm{z}$ - value is 1.96 as per the normal table, so using the following formula, appropriate sample size was determined.

Sample Size $=\frac{z^{2} p q q}{e^{2}}$

Where,

- $\quad e$ is the desired precision limit

- $\quad p$ is the (assumed) proportion of the population which prefer online shopping,

- $\quad q$ is $(1-p)$

Sample Size $=\frac{1.96^{2} \cdot(0.5)(0.5)}{0.08^{2}}=150.0625(150$ Approximately)

\section{DATA ANALYSIS AND INTERPRETATION}

To calculate the attitude score of the first respondent for online shopping and offline shopping, the evaluation scale value for each attribute (Described in V.A) is multiplied by the corresponding belief scale value and the sum of all these products are taken. The resultant is the overall score of the respondent's attitude. Table no. 1, 2, and 3 depict the computation of initial respondent's overall attitude score for each mode of shopping.

The respondent rated each attribute of shopping on the evaluation of attribute scales to indicate the intensity of his feelings about each attribute $i$ as being important or unimportant. This is denoted by $\mathrm{E}_{\mathrm{i}}$ and shown in table-1.
Table-1: Attribute Rating by First Customer

\begin{tabular}{|c|c|c|c|c|c|c|c|}
\hline Attribute $\left(\mathrm{A}_{\mathrm{i}}\right)$ & $\mathrm{A}_{1}$ & $\mathrm{~A}_{2}$ & $\mathrm{~A}_{3}$ & $\mathrm{~A}_{4}$ & $\mathrm{~A}_{5}$ & $\mathrm{~A}_{6}$ & $\mathrm{~A}_{7}$ \\
\hline Rating $\left(\mathrm{E}_{\mathrm{i}}\right)$ & 7 & 7 & 7 & 7 & 6 & 6 & 6 \\
\hline
\end{tabular}

The respondent rated the association of attribute and each shopping mode on the attribute and shopping mode linkage scales to indicate the strength of his belief about the linkage of each attribute and mode of shopping. This is denoted by $B_{i}$ and shown in table-2.

Table-2: Beliefs Rating by First Customer

\begin{tabular}{|l|c|c|c|c|c|c|c|}
\hline Attribute $\left(\mathrm{A}_{\mathrm{i}}\right)$ & $\mathrm{A}_{1}$ & $\mathrm{~A}_{2}$ & $\mathrm{~A}_{3}$ & $\mathrm{~A}_{4}$ & $\mathrm{~A}_{5}$ & $\mathrm{~A}_{6}$ & $\mathrm{~A}_{7}$ \\
\hline $\begin{array}{l}\mathrm{B}_{\mathrm{i} .} \text { for Online } \\
\text { Shopping }\end{array}$ & 6 & 4 & 7 & 5 & 6 & 4 & 7 \\
\hline $\begin{array}{l}\mathrm{B}_{\mathrm{i} . \text { for Offline }} \\
\text { Shopping }\end{array}$ & 7 & 7 & 7 & 7 & 7 & 7 & 6 \\
\hline
\end{tabular}

Overall attitude score for online and offline shopping modes are calculated by using the relation $A_{0}=\sum B_{i} . E_{i}$ and shown in table-3.

Table 3: Spreadsheet- First Customer's Attitude Scores for online and offline shopping.

\begin{tabular}{|c|c|c|c|c|c|}
\hline $\begin{array}{l}\text { Attribute } \\
\left(\mathrm{A}_{\mathrm{i}}\right)\end{array}$ & $\begin{array}{c}\text { Rating } \\
\left(\mathrm{E}_{\mathrm{i}}\right)\end{array}$ & $\begin{array}{c}\mathrm{B}_{\mathrm{i}} \text { for } \\
\text { Online } \\
\text { Shopping }\end{array}$ & $\begin{array}{c}\mathrm{B}_{\mathrm{i}} \mathrm{E}_{\mathrm{i}} \text { for } \\
\text { Online } \\
\text { Shopping }\end{array}$ & $\begin{array}{c}\mathrm{B}_{\mathrm{i}} \text { for } \\
\text { Offline } \\
\text { Shopping }\end{array}$ & $\begin{array}{c}\mathrm{B}_{\mathrm{i}} \mathrm{E}_{\mathrm{i}} \text { for } \\
\text { Offline } \\
\text { Shopping }\end{array}$ \\
\hline $\mathrm{A}_{1}$ & 7 & 6 & 42 & 7 & 49 \\
\hline $\mathrm{A}_{2}$ & 7 & 4 & 28 & 7 & 49 \\
\hline $\mathrm{A}_{3}$ & 7 & 7 & 49 & 7 & 49 \\
\hline $\mathrm{A}_{4}$ & 7 & 5 & 35 & 7 & 49 \\
\hline $\mathrm{A}_{5}$ & 6 & 6 & 36 & 7 & 42 \\
\hline $\mathrm{A}_{6}$ & 6 & 4 & 24 & 7 & 42 \\
\hline $\mathrm{A}_{7}$ & 6 & 7 & 42 & 6 & 36 \\
\hline$\sum \mathrm{B}_{\mathrm{i}} \cdot \mathrm{E}_{\mathrm{i}}$ & & & 256 & & 316 \\
\hline
\end{tabular}

Similarly, overall attitude scores for other 149 respondents are calculated through the use of MS-Excel.

A.

B. A. Testing of Hypothesis-1

After calculating the attitude scores of the selected respondents for online and offline shopping modes, two independent samples of attitude scores are used to verify the first hypothesis through the application of Two samples z-Test.

The pair of null and alternative hypotheses is

$\mathbf{H}_{\mathbf{0}}$ : Customers' mean attitude score for online shopping is equal to their mean attitude score for offline shopping

$\mathbf{H}_{1}$ : Customers' mean attitude score for online shopping is more than that for offline shopping.

To test $\mathrm{H}_{0}$ against $\mathrm{H}_{1}, 95 \%$ confidence level is taken (i.e. the level of significance is 0.05 ). The output produced by MS-Excel is shown in table-4. 


\section{A Research on Customers' Attitudes and Their Preferences Toward Online Shopping Vis-à-vis Offline Shopping with Special Reference to Electric and Electronic Products in India}

Table-4: z-Test of two samples means (MS-Excel output)

At $95 \%$ confidence level $(\alpha=0.05)$, the critical value of $\mathrm{z}$ is 1.645 for right-tailed test. The computed value of $\mathrm{z}$ is 6.2002 which is more than the critical value and falls in the rejection region of the sampling distribution. Hence, the decision is to reject the null hypothesis. Acceptance of alternative hypothesis implies that Customers' mean attitude score for online shopping is more than that for offline shopping. This indicates that customers' attitudes toward online shopping are more favorable than their attitudes toward offline shopping.

\section{B. Testing of Hypothesis-2}

To test the second Hypothesis, one sample proportion z- Test is applied through MS- Excel.

The pair of null and alternative hypotheses is

$\mathbf{H}_{\mathbf{0}}$ : Proportion of customers who prefer to shop online is equal to $50 \%$.

$\mathbf{H}_{1}$ : Proportion of customers who prefer to shop online is more than $50 \%$.

To test $\mathrm{H}_{0}$ against $\mathrm{H}_{1}, 95 \%$ confidence level is taken (i.e. level of significance is 0.05 ). The output produced by MS-Excel is shown in the following table.

Table-5: z- Test of one sample proportion, (MS-Excel output)

\begin{tabular}{|c|c|}
\hline \multicolumn{2}{|l|}{ Frequency: 68} \\
\hline \multicolumn{2}{|l|}{ Sample size: 150} \\
\hline \multicolumn{2}{|c|}{ Test proportion : $45.33 \%(0.453)$} \\
\hline \multicolumn{2}{|c|}{ Hypothesized mean difference : 0} \\
\hline \multicolumn{2}{|c|}{ Variance (confidence interval) : Test proportion } \\
\hline \multirow{2}{*}{\multicolumn{2}{|c|}{$\begin{array}{l}\text { Significance level }(\%): 5 \\
95 \% \text { confidence interval on the proportion (Wald): } \\
\text { ] } 0.454 ; 0.812 \text { [ }\end{array}$}} \\
\hline & \\
\hline Difference & 0.133 \\
\hline $\mathrm{z}$ (Observed value) & 1.1418 \\
\hline $\mathrm{z}$ (Critical value) & 1.6450 \\
\hline p-value (one-tailed) & 0.079 \\
\hline alpha & 0.05 \\
\hline
\end{tabular}

At $5 \%$ level of significance $(\alpha=0.05)$, the critical value of $\mathrm{z}$ is 1.6450 for right-tailed test. The computed value of $\mathrm{z}$ is 1.1418 which is less than the critical value and falls in the acceptance region of the sampling distribution. Hence, the decision is to accept the null hypothesis. It means that almost or exactly half of the population of customers in Dehradun city prefers to shop electric and electronic products online.

\section{RESULT AND DISCUSSION}

Statistical analysis of data rejects first null hypothesis which implies that there is no evidence of any insignificant difference in customers' attitudes toward online and offline shopping modes for electric and electronic products. This result indicates that the customers' attitudes toward the online mode of shopping for electric and electronic products are more favorable than their attitudes toward offline shopping mode. Acceptance of the second null hypothesis through statistical analysis implies that almost half of the population of customers prefers to shop electric and electronic products

\begin{tabular}{|l|r|r|}
\hline & \multicolumn{1}{|c|}{ Variable- 1 } & Variable- 2 \\
\hline Mean & 272.562 & 246.513 \\
\hline Known Variance & 1704.557 & 942.614 \\
\hline Observations & 150 & 150 \\
\hline $\begin{array}{l}\text { Hypothesized Mean } \\
\text { Difference }\end{array}$ & 0 & \\
\hline z & 6.2002 & \\
\hline P(Z<=z) one-tail & $2.819 \mathrm{E}-10$ & \\
\hline z Critical one-tail & 1.645 & \\
\hline $\mathrm{P}(\mathrm{Z}<=\mathrm{z})$ two-tail & $5.638 \mathrm{E}-10$ & \\
\hline $\mathrm{z}$ Critical two-tail & 1.960 & \\
\hline
\end{tabular}

online. These findings can be generalized and it can be said that, as far as electric and electronic products are concerned, almost all the features/ attributes of shopping (namely Availability of variety of products, Facility to evaluate and compare the available variants, Mode of payment, Return and Exchange policy, Discount and Promotion offers, Guarantee of quality of products, and Home delivery) are equally important for the customers i.e. intensity of their feelings (liking or disliking) for each selected feature is identical but customers do not possess similar beliefs about the linkage of the features of shopping and each shopping mode. Therefore, customers hold more favourable attitudes toward online shopping than offline shopping while purchasing electric and electronic products.

\section{CONCLUSION}

Based on the findings of the investigation, it is concluded that the belief of the marketers that online shopping has become a popular way of shopping for the customers because of their changing attitudes and adoption of technological change is true in the context of electric and electronic products. Customers believe that all the important attributes of shopping function are strongly associated with online shopping mode and they prefer to shop electric and electronic products online. Now is the right time for the marketers to devise their strategies to accord with customers' preference and to meet their demand.

\section{REFERENCES}

1. N.J Jemila Dani, “A Study on Consumers' Attitude Towards Online Shopping" International Journal of Research in Management \& Business Studies, vol.4, 2017, pp. 42- 46.

2. P. Kothari and S.S. Maindargi, "A Study on Customers Attitude towards Online Shopping in India and its Impact: With Special Reference to Solapur City", International Journal of Advance Research, Ideas and Innovations in Technology, vol. 6, 2016, pp. 1-10

3. A. Agift, V. Rekha, and C. Nisha, "Consumers attitude towards online shopping", Research Journal of Family, Community and Consumer Sciences, vol. 08, 2014, pp. 1-07.

4. Dr. R. Sharma, Dr. K. Mehta, and S. Sharma, "Understanding Online Shopping Behaviour of Indian Shoppers", International Journal of Management \& Business Studies, vol. 4, 2014, pp. 9-18 
5. W. Gong, L.M. Maddox and L. Stump Rodney, "Attitudes toward Online Shopping: A Comparison of Online Consumers in China and the US", International Journal of E-Business Development, vol. 2, 2012, pp. 28-35

6. B. Michael, G. Mirtra, and T. Tracy, "Personality Determinants of online shopping: Explaining Online Purchase Intentions using a Hierarchical Approach", Journal of Business Research, vol. 15, 2007, pp. 597-605.

7. J. Kim, A. Fiore, and H. Lee, "Influences of online store perception, shopping enjoyment, and shopping involvement on consumer patronage behavior towards an online retailer", Journal of Retailing and Consumer Services, vol. 14, 2007, pp. 95-107

8. S.S. Gurvinder and C. Zhaobin, "Web-Based Shopping: Consumers' Attitudes towards Online Shopping In New Zealand", Journal of Electronic Commerce Research, vol. 14, 2005, pp. 651-648.

9. V. Mummalaneni, "An empirical investigation of Web site characteristics, consumer emotional states and on-line shopping behaviors", Journal of Business Research, vol. 58, 2005, pp. 526-532.

10. R. Andrew and S. Vanitha, "A typology of online shoppers based on shopping motivations", Journal of Business Research , vol. 57, 2004, pp. $748-757$

11. B. Amit and S. Ghose, "A latent class segmentation analysis of e-shoppers", Journal of Business Research. Vol. 57, 2004, pp. 758-767.

12. K. P. Chian and R.R. Dholakia, "Factors Driving Consumer Intention to Shop Online: An Empirical Investigation", Journal of Consumer Psychology, vol. 13, 2003, pp. 177-183.

13. R. Baker and P. Wallage, "Testing variations of Fishbein's behavioral intention model within a consumer behavior context", Journal of consumer psychology, vol. 62, 2000, pp. 52-57.

14. R. E. Goldsmith and E. Bridges, "Using attitudes to predict online buying behavior" Quarterly Journal of Electronic Commerce, vol. 1, 2000, pp. 245-253

15. C. Kelly and S. Breinlinger "Attitudes, Intentions, and Behavior: A Study of Women's Participation in Collective Action". Journal of Applied Social Psychology, vol. 25, 1995, pp. 430-445.

16. https;//www.statista.com/studies-and-reports/\#panelSurveys.

\section{AUTHORS PROFILE}

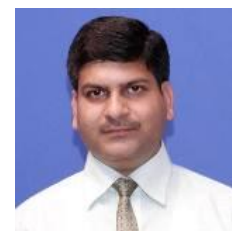

Anil K.S. Chauhan is presently working as Assistant Professor in Uttaranchal Institute of Management, Uttaranchal University, Dehradun. He has more than

17 years of teaching and industry experience. $\mathrm{He}$ possesses M.Sc. (Mathematics), MBA, and M. Phil. (Management) degrees and currently pursuing $\mathrm{PhD}$ in Management. He has supervised several MBA Dissertation Projects. He has attended several seminars, workshops and conferences at various levels. He has 15 research papers published in various national and international journals. His area of interest in teaching and research includes Consumer Behavior, Business Research, Marketing Research, Operations Management and Operations Research

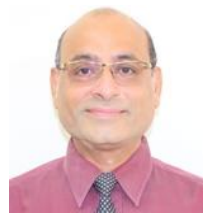

Dr. Pradeep Suri is presently working as Professor and Director in Uttaranchal Institute of Management, Uttaranchal University, Dehradun. He has more than 29 years of teaching, industry and administrative experience. He possesses M.Com, ICWA, MBA and $\mathrm{PhD}$ degrees. He has also qualified UGC-NET and USET. He has supervised more than 15 research scholars of various universities. He has attended several seminars, workshops and conferences at various levels. He has more than 30 research papers published in various national and international journals. His area of interest in teaching and research includes Security and Portfolio Management, Financial Management, International Financial Management, Marketing Research, and Marketing Management. 